PROCEEDINGS OF THE WORLD CONFERENCE ON OZONE THERAPY IN MEDICINE, DENTISTRY AND VETERINARY. ANCONA (ITALY). SEPTEMBER 22nd - 23rd - 24th, 2017

\title{
Analysis of 82 cases of spinal cord injury treated by ozone [abstract]
}

\author{
Xirzat Abdukeram¹, Muhtar Rixit², Dilare Mahmut²

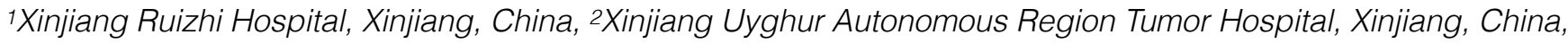

\section{ABSTRACT}

\section{O OPEN ACCESS \\ Citation \\ Abdukeram X, Rixit M, Mahmut D. Analysis of 82 cases of spinal cord injury treated by ozone [abstract]. Proceedings of The World Conference on Ozone Therapy in Medicine, Dentistry and Veterinary. Ancona (Italy). September 22nd - 23rd - 24th , 2017. J Ozone Ther. 2019;3(4):84. doi: 10.7203/jo3t.3.4.2019.15573}

\section{Academic Editor}

Jose Baeza-Noci,

School of Medicine, Valencia University, SPAIN

\section{Editor}

World Federation of Ozone Therapy, Bolgna, ITALY

\section{Received}

June 17, 2019

\section{Accepted}

December 08, 2019

\section{Published}

December 30, 2019

\section{Intellectual Property}

Xirzat Abdukeram.

This is an open access article distributed under the terms of the Creative Commons Attribution License (CC BY 4.0), which permits unrestricted use, distribution, and reproduction in any medium, provided the original author and source are credited.

\section{Author Information} ozonetherapy@126.co
Purpose. To investigate the feasibility and clinical efficacy of ozone in the treatment of spinal cord injury so as to restore the function and sensation of the limbs.

Methods. From May 2007 to July 2016, 82 patients with spinal cord injury were treated, including 24 females and 58 males, with an average age of 32.1 years.

Among all the research, 26 cases of cervical spinal cord injury, 12 cases of paraplegia in the thoracic spinal cord, 44 cases of paraplegia in the lumbar spine, all of whom had muscle strength 0 and had incontinence.

Frankel classification, grade $A$ is 69 cases, $B$ class is 13 cases.

12 cases of spinous process wire fixation was performed; in 61 cases, internal pedicle screw fixation, and no internal fixation was required in 9 cases. In these patients, we did epidural injection of $2-8 \mathrm{~mL}$ of ozone at $35 \mu \mathrm{g} / \mathrm{mL}$ with the $\mathrm{C}$ arm.

In 4 cases we did spinal canal decompression and internal fixation and we used an epidural catheter into the epidural and subarachnoid cavity to directly inject 2-8 $\mathrm{mL}$ of ozone at $35 \mu \mathrm{g} / \mathrm{mL}$; after catheter withdrawal, we did ozone injection in the scar segment with the $C$ arm to increase acurracy of the technique.

Results. In 10 patients, the treatment produced no neurological improvement; the remaining 72 patients, from the $3^{\text {rd }}$ postoperative day, feeling started to recover. We observed 22 patients during 26 months that could stand up and walk with crutches and 18 patients of them could control defecation and 16 patients could feel the defecation; 14 cases could do slight activities with their lower extremities; 12 patients reached mild forearm movement.

Conclusion. The key to the repair of the injured spinal cord is provided through the axon growth; ozone can play a worthy role in the release of scar and allow nerve axons to grow and access some function recovery. 